\title{
Physical Quality of Life Benchmark for Unsafe Slums in Egypt
}

\author{
Heba A. ElFouly ${ }^{1 *} \&$ Noha A. El Aziz ${ }^{1}$ \\ ${ }^{1}$ Lecturer at urban design department, Faculty of Urbanand Regional Planning, Cairo University, Egypt \\ *Heba A. ElFouly, E-mail: Heba.elfouly@gmail.com
}

Received: May 15, 2017

doi:10.22158/se.v2n2p258
Accepted: May 26, 2017

Online Published: May 31, 2017

URL: http://dx.doi.org/10.22158/se.v2n2p258

\begin{abstract}
Enhancing the quality of life in urban settle ments is one of the most significant challenges facing governments. In the case of unsafe-slums, the challenge is even more problematical, as slum dwellers not only suffer from substandard housing, devoid of basic necessities and unhealthy urban conditions, but they are exposed to danger. This paper focuses on extracting the most significant physical QoLindices in unsafe-slums in Egypt, taking into account the limited designated investments and the temporary situation of suchslums. Interviews with central governments (ISDF, GOPP), local authorities (Cairo and Gizagovernates), and urban planning experts were conducted, in addition to secondary data collected from reports andresearches. The study reveals that the first priority to uplift the QoL, is to reserve the household health by providing adequate and low-cost water supply, sanitation and solid waste management. While enhancing services, housing condition and increasing economic activities is not prompt, as it probably will result in rooting the community to unsafe neighborhoods. Finally, the study proposed a paradigm that differentiates between the QoLbench mark for unsafe slums subjected to relocation strategies and other types of slums to be upgraded and developed.
\end{abstract}

\section{Keywords}

Quality of life in slums, unsafe slums, QoL benchmark, physical QoL

\section{Introduction}

The world is undergoing a tremendous wave of urban growth, in 2008, more than half of the world's population was living in cities. By 2030 this number will increase to almost 5 billion, principally in Africa and Asia (Jha \& Tripathi, 2014). Nearly one billion people currently live in slums, and this number is expected to grow tonearly 500 million by 2020 (Patel, 2014). Slums are one of the most complicated challenges facing many cities all over the world (Amao, 2012) as the illegal informal housing developmentin slums pose a formidable pressure in many developing countries (Owoeye \& Ogundiran, 2015). Robert McNamara, the former president of World Bank, declared that "If cities do not deal with the problems of the slums in a constructive way, they will deal with the cities in a 
destructive way" (Sundari, 2013). Slums are associated with a variety of problems, including pollution, poor planning and housing conditions resulting in scattered developments, limited access to services such as schools, health centers, and market places. Additionally, infrastructure like water supply, sanitation, electricity, roads and drainage are below minimum levels (Owoeye \& Ogundiran, 2015; UN-HABITAT, 2003). Unfortunately, the situation is worst in developing countries like Egypt, where the magnitude of slum population is rapidly increasing and has outstripped the capacity to maintain acceptable standards of physical infrastructure, environmental safety, and housing quality.

Although the term "unsafe slum area" is not internationally used as a definite type of slum areas (as used in the Egyptian context), yet it can be induced from the general definition adopted by the UN Habitat (2008). Slums are recognized as the manifestation of one or more of five shelter deprivations (poor access to water, poor access to sanitation, substantial dwellings, deficient living area, and insecurity of tenure). Accordingly, slums have been categorized into: moderately deprived (one shelter deprivation), severely deprived (two shelter deprivations), and finally, the extremely deprived (three or more shelter deprivations) which could generallyrefer to the Egyptian situation of the "unsafe slum areas" (Khalifa, 2011). Most of the unsafe slums in Egypt are subjected torelocation or clearance policies, resulting in abandon and lack of investments, fundamentally affecting the QoLof the marginalized dwellers. Another problem is the ambiguous definition of quality of life and the lack of appropriate indicators to determine the minimum standards accepted in temporary slums. From the preceding predicaments arises the research quest to determine the minimum physical QoL indicators that affect the quality of life of the dwellers directly, without jeopardizing attaching the community to unsafe places or depleting resources and investments.

\section{Literature Review: Quality of Life in Unsafe-Slums}

The term "Quality of life" (QoL) is used to evaluate the general well-being of individuals and societies, but it is very complex, very comprehensive, and it varies with time and the place (Bradburn, 1969). The World Health Organization (WHO) defined QoL as "the Individual's perception of their position in life in the context of the culture and value system in which they live and in relation to their goals, expectations, standards and concerns" (Moser, 2009). Quality of life is acomprehensive concept that includes consideration of economic development, social vitality, and environmental health (Hardi \& Pinter, 2007). Studies on QoL emerged in the 1960s asa tool for measuring development, that had been prior the sixties linked exclusively to economic growth and GDP per capita (Darkey \& Kariuki, 2013). Today it is realized that GDP cannot alone explain the broader quality of life (Jha \& Tripathi, 2014). Indicators are set at global and national levels to measure and assess the effectiveness of recent policies and to design new ones as necessary. Regarding the evaluation of QoL, today it means not only satisfaction or the availability of resources but also easy access and the ability to make use of opportunities (Craglia et al., 2004). 


\subsection{Measuring Quality Life}

There are a wide variety of indicators to measure Quality of Life. Nevertheless, the extensive indicators can be categorized into subjective indicators, where people express their satisfactionor dissatisfaction with the conditions surrounding them, as evaluating or ranking the perceivedsafety in a neighborhood. The other set of indicators is objective indicators, that can be fairly quantified and defined; these indicators offer a privileged of cross-section comparison, as energy use in kilowatt hours/year (Darkey \& Kariuki, 2013; Hardi \& Pinter, 2007). Combining both indices helps to understand and formulate a better perspective of QoL. For instance, some would be satisfied with the QoL though they are living under tough environmental conditions, while others would rate their QoL as poor even though the environmental conditions they live in are excellent (Westaway, 2006). As for QoL indexes, different models seek to measure the overall experience of life, for example, not limited to: Johnston's QoL Index; Miringoff's Index of Social Health; Calvert-Henderson Quality of Life index. Moreover, Netherlands Living Conditions Index; German System of Social Indicatorsand Economist Intelligence Unit's Quality of Life Index are used to assess QoL (Jha \& Tripathi, 2014).

QoLindexes commonly cover social indicators as, shelter and infrastructure, health and nutrition, education and lifelong learning, access to services and resources, freedom from fear, human rights, cultural vitalityand civic engagement, enrichment and innovation. Additionally, the QoL indexes cover environmental indicators such as, quality of air, quality of the water in natural bodies, and other natural resources, while the economic indicators measure the economic well-being, income distribution, employment rates, access to energy and economic prosperity (Amao, 2014; Diener \& Suh, 1997; Flynn, Berry \& Heintz, 2002). Further interesting paradigm is presented by (Doi, Kii, \& Nakanishi, 2008), where QoL indicators are ranked based on Maslow's hierarchy of needs (Figure 1).
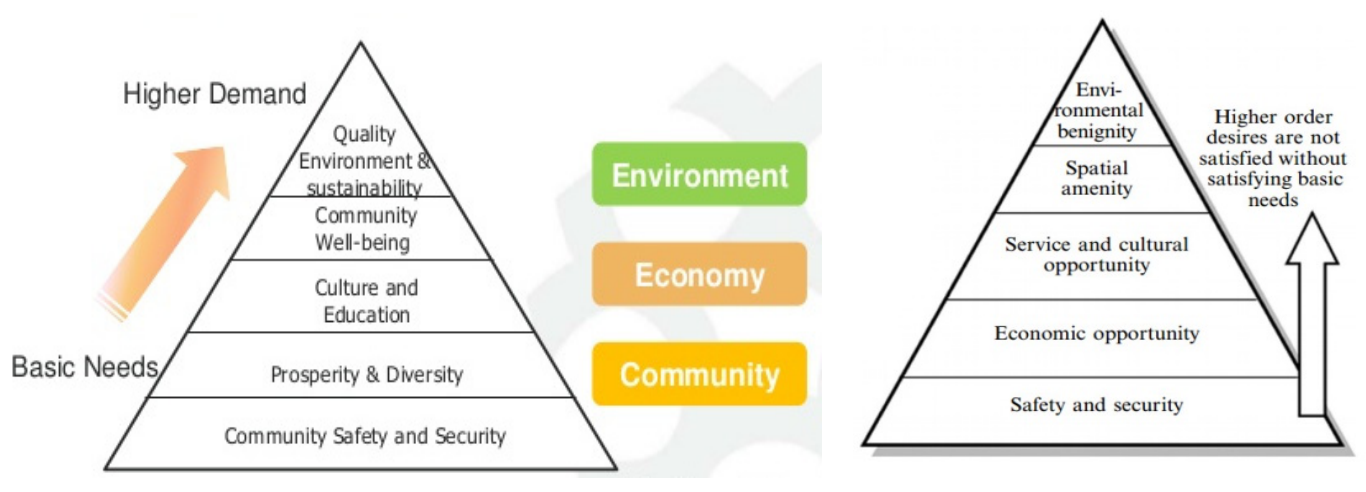

Figure 1. QoL Dimensions Ranked According to Maslow's Hierarchy of Needs

Source: Doi, Kii and Nakanishi, 2008.

The paradigm considers satisfying the most basic needs "Safety and Security" mandatory for accomplishing the satisfaction of higher needs. Economic Opportunity is the second basic need, service Published by SCHOLINK INC. 
and cultural opportunity follow. As for Spatial Amenity, and Environmental Benignity, they are the higher-order desires. Minimizing the rate of traffic accidents, vulnerability to natural disasters, access time to emergency care centers are indicators of the extent to which the community is safe and secured. Economic Opportunity indices comprise local employment rates, the number of domestic and international tourists. The Service and Cultural Opportunity are considered with the availability of large-scale retail stores, cultural services and the efficiency of public transportation. Spatial Amenity tackles housing conditions, open spaces, landscape and urban design. Finally, Environmental Benignity indices addressair quality, and the mitigation of water pollution.

\subsection{The Quality of the Physical Environment in Slums}

In 2000, the UN developed eight goals "Millennium Development Goals" in order to improve the lives of the world's poorest people. One of these goals is to ensure environmental sustainability in slum areas. This goal concentrates on enhancing the quality of life of people living in slums, as it targeted adopting sustainable development, providing sustainable access to safe drinking water and basic sanitation, and finally durable and less crowded housing (UN Organization, 2015). The link between the physical components of the residential environment and quality of life of its dwellers is undeniable, manifesting from the housing unit to the whole urban setting. Changing the urban form and the built environment are associated with lifestyle and behavioral change that affect the quality of life (Nakanishi, 2013). Consequently, it is possible to enhance the QoL of slum dwellers through upgrading their urban environment. The correlation analysis in a study by (Amao, 2014) reveals a significant relationship exists between the quality of life and some physical variables like ventilation, lighting, spaces, aesthetic, security, drainage, landscape, sanitation, type of construction materials and the external environment of the house. The study results infer that QoL tends to increase as the physical condition improves. The major challenge is to determine the appropriate indicators and benchmark that would able to upgrade the QoL in the slums. Table 1 illustrates the main physical attributes in the QoL.

Table 1. Physical Environment QoL Dimensions

\begin{tabular}{lll}
\hline Parameters & Goals & Physical Dimensions \\
\hline Environmental & Safety & Land contamination \\
& Natural environment quality & Land stability \\
& Air quality \\
Biodiversity & Water bodies quality \\
Health & Natural Landscapes and parks \\
& Drinking water quality and access \\
& Drainage \\
& Sanitation \\
& Solid waste management \\
\hline
\end{tabular}




\begin{tabular}{lll}
\hline Social & Shelter & Density \\
& Ventilation \\
& Lighting & Area, design and materials \\
& Privacy \\
& Mobility & Street quality \\
& Walkable Network \\
& & Accessible public transportation \\
& Vducation & Variety of Transportation Choices \\
& Heath & Educational services \\
Social interaction & Health services \\
& Cultural and recreational services \\
& Culture & Commercial services \\
\hline Economic & Income & Social services \\
& & Job opportunity \\
& Energy efficiency
\end{tabular}

Source: Researchers.

\section{Slums within the Egyptian Context}

Slums in Egypt are widelyspreading inside the urban fabric; representing 37\% of the country's urban population and $20 \%$ of the total population (ISDF, 2014). Being deprived of utilities and densely populated with limited social services, slums have become one of the main challenges within the Egyptian context (GOPP, 2012). However, the Egyptian government reaction towards slums was limited to few cases of ad-hoc clearance and resettlement, until the Doweiqa landslide disaster in 2008. The landslide tragedy resulted in the death of more than 100 person (Sims, 2010). Consequently, the government adopted a more institutional strategic approach, by establishing the Informal Settlements Development Facility (ISDF). The principal aim of the (ISDF) is to coordinate efforts and finance the development of a national strategy to tackle slums and ensure safe housing (ISDF, 2009a). In this context, ISDF has made a significant change in the ideology of dealing with slums by replacing the common terms: "Slums", "Informal Settlements" or "Ashwa' iyyat" by two distinctive terms: "Unsafe Areas" and "Unplanned areas" (Khalifa, 2011).

According to ISDF (2009b), unsafe areas are those which include 50\% or more of residential buildings with unsafe standards, while unplanned areas are the safe areas which are not compliant with neither planning regulations nor building laws. Contextually, unplanned areas comprise $85-90 \%$ of slum areas, and $60 \%$ of total urban areas. Average density in slums reaches 500 person/acre, the building heights range from 4-10 floors, and need medium or long term upgrading approaches. Unsafe areas, on the 
other hand, occupy $10-15 \%$ of slum areas, and $1 \%$ of total urban areas, with an average density of 200 person/acre. Building heights range from 1 to2floors and require deliberate intervention (El-Framawy \& Algohary, 2011). Being exposed to life threats, or hosting inappropriate housing stock, or exposed to health threat or tenure risks, unsafe areas are categorized, by ISDF, into four types (grades) according to the degree of risk and, thus, the urgency of intervention (Table 2).

Table 2. Types of Unsafe Areas and Their Corresponding Interventions

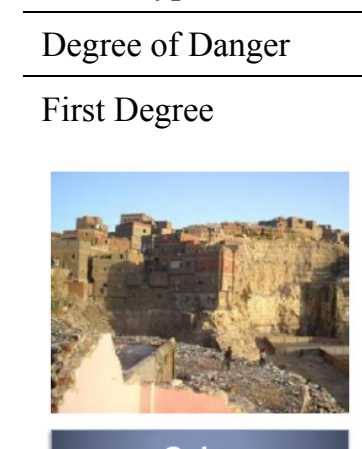

Cairo
Second Degree

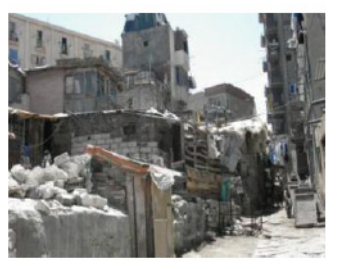

Alexandria

Third Degree

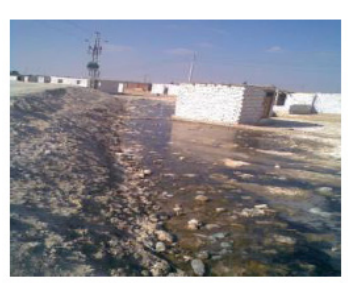

Baheira
Areas of unsuitable shelter conditions including:

- Buildings made makeshift materials.

- Sites unsuitable for building.

Areas which threaten the public health:

- Lacking access to clean drinking water or improved sanitation.

- $\quad$ Located in the vicinity of industrial pollution.

- Located under electrical power lines.
Type of intervention

- Displacement

is compulsory; where people should be relocated in safe housing provided by the government or get appropriate monetary compensation.

- The location is exposed

to railway accidents.

- In-situ housing replacement with densification or displacement to nearby state-owned land.

- Monetary compensation (19) - Transfer or conversion of aerial power lines to land cable in cooperation with concerned Ministries and Governorates.

- Regularization of polluting factories by the collaborationbetween the Ministry of Environment and the Ministry of Industry.

- The implementation of safe water supply systems and sanitation facilities. 


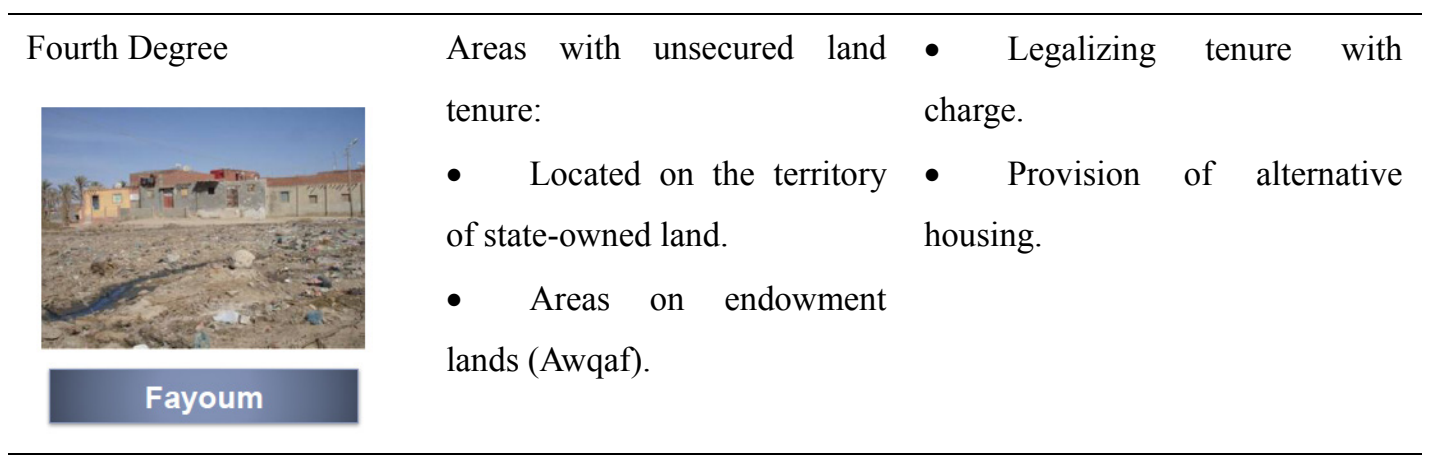

Source: Researchers, after ISDF, 2010.

Finally, it is clear that the most dangerous type of slums in Egypt is the unsafe areas, where their residents face considerable dangers; whether by being subject to life hazard, or having unsuitable housing, or exposed to health threat or tenure risks. Accordingly, interventions towards unsafe areas are generally based on clearance and relocation in new housing projects either on the same site (but safe) or in one of the new cities.

\section{Research Materials and Methods}

\subsection{Study Area}

Being the beating heart of Egypt, with approximately $20 \%$ of the country's total population, the Greater Cairo Region (GCR) is considered to be the biggest and most influential urban area in the Middle East and the African continent. According to recent studies, the existence of slum areas (both unplanned and unsafe slums) is the largest challenge facing GCR: the unplanned slum areas cover about $40 \%$ of the GC area, with a total area of 22500 acres, which continue to grow at an annual rate of $2.5 \%$ mainly on agricultural lands. The unsafe slum areas, on the other hand, cover about 1058 acres, of total 100 areas, including more than 61,000 housing units (GOPP, 2012). As shown in (Figure 3), more than a quarter of the total unsafe areas all over Egypt $(\mathrm{n}=422)$ is detected in the GCR (ISDF, 2012 cited in AUC, 2014).

Based on a study conducted by Japan International Cooperation Agency JICA (2011), it has been found that there is an extreme deficiency in housing conditions, utilities, and services, shaping the main physical characteristics of unsafe areas in GCR (Figure 4). 


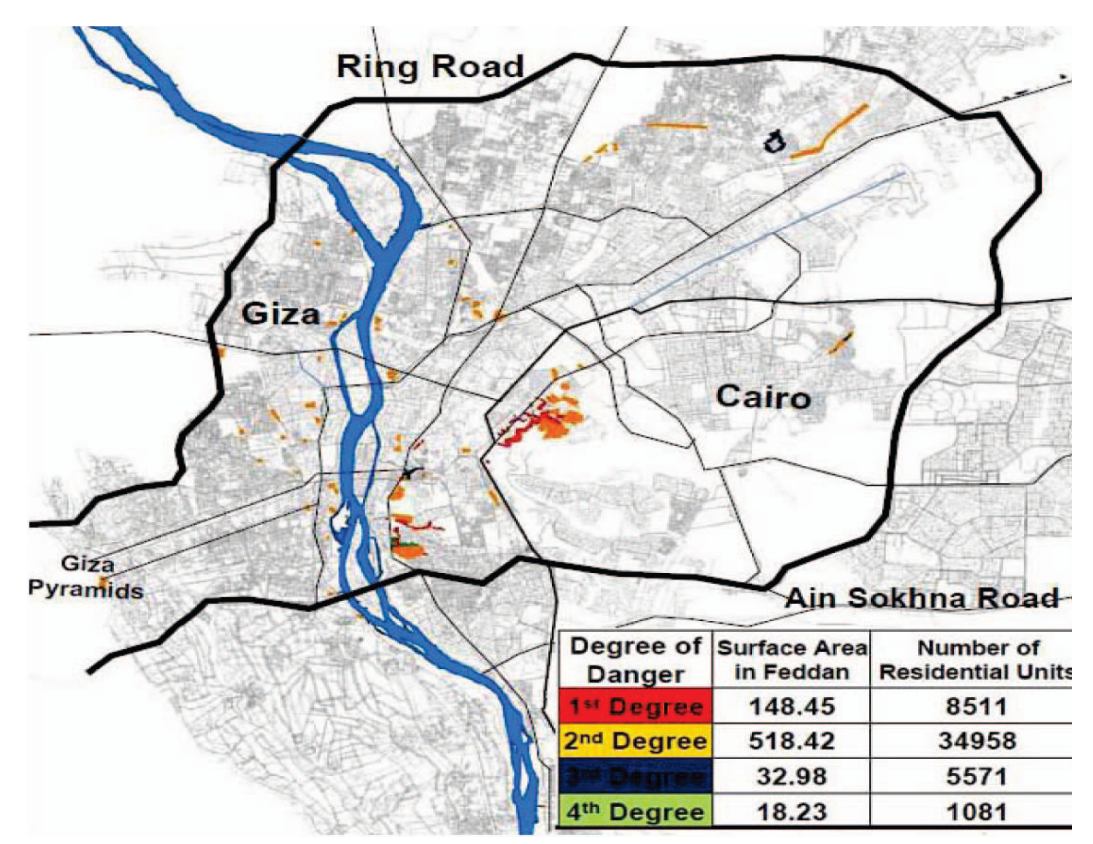

Figure 2. Types of Unsafe Slum Areas in GCR

Source: GOPP, 2012.

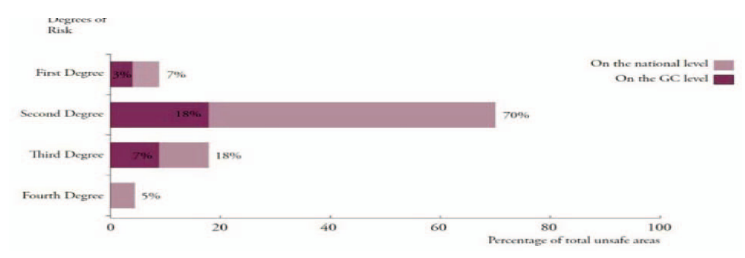

Figure 3. Classification of Unsafe Areas by Degree of Risk and Location

Source: ISDF, 2012 cited in GOPP, 2012.

-Housing buildings are mostly temporary; built using second-hand or lightweight construction materials, such as tin or used wood, depending on the nature of each site. Housing Occupies more than $90 \%$ of the total area. Therefore, open spaces are very rare, shaping a very compact fabric. Moreover, population density is extremely high; as mostly the whole family (five to eight people) lives in one room.

-Public utilities and roads are incompetent; basic infrastructure services such as drinking water supplies, sanitation services and electricity supplies are unavailable; poor unpaved, narrow roads (generally between three and sixmeters width) are detected, piled by garbage, solid wastes. However, most unsafe areas are located close to main streets or railway lines, allowing residents to walk to the nearest point of transportation.

-Public and social services (such as schools, clinics, hospitals and public gardens) are not found, and ifexist, they are usually insufficient in number.

Consequently, most of the unsafe areas in GCR suffer from environmental deterioration and very low 
standard of living conditions.

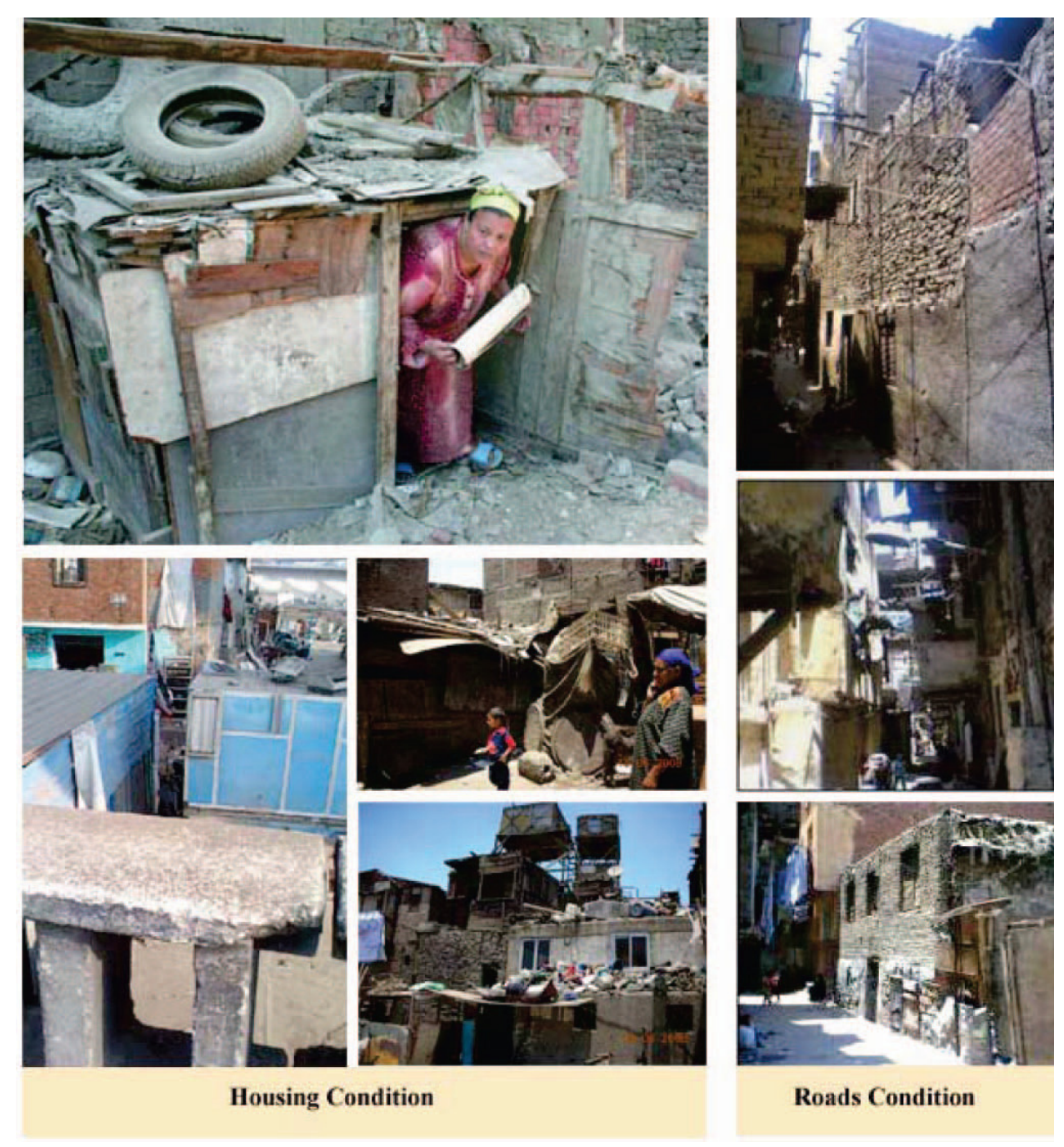

Figure 4. Signs of Deterioration of the Unsafe Areas

Source: Researchers.

\subsection{Methods}

The aim of this research is to identify benchmarks of the quality of the physical environment in unsafe slums in the GCR. It seeks to ensure the minimum QoL without rooting the community to unsafe neighbourhoods, in order to facilitate the transition process to safer environments. In this context, the unsafe areas of first degree, which deal with life threats, are excluded from this study as the immediate displacement is compulsory and, hence, the temporary state is not applied in this case. The rationale beyond focusing the study within the GCR is two-fold: first, it accommodates more than $50 \%$ of the Country's total slum areas (CAPMAS, 2008), and 25\% of the country's total unsafe slum areas (ISDF, 2012 cited in AUC, 2014). Second, it is the most organized region (which includes both Cairo and Giza governates), with highly trained representatives compared to the rest governates in Egypt and, hence, 
its representatives would be the most qualified local authority members in Egypt.

The study was undertaken with the following objectives:

- To determine substantial QoL indicators and bench mark in unsafe slum areas.

- To suggest an inclusive paradigm of QoL for slum areas with respect to the different types and interventions.

Data collection consolidate primary and secondary data: Primary data are obtained by means of semi-structured interviews, while secondary sources include previous publications, governmental official statistics, and reports. Face-to-face semi-structured interviews are conducted with twenty participants purposively selected from three different parties:

- The central government, represented in Informal Settlements Development Fund (ISDF) ( $\mathrm{n}=4$ ), and General Organization for Physical Planning (GOPP) ( $\mathrm{n}=4$ ), which are both responsible for setting the National Slums Strategies as well as identifying the national intervention priorities.

- The local authority, represented in Cairo governate $(n=3)$, and Giza governate $(n=3)$ which are responsible for implementing the National Slums Strategies as well as setting its local intervention priorities.

- Urban planning experts $(n=6)$ who play a crucial role as the technical supporter for both the central and local authorities.

The QoL dimensions, evolved from literature review, were discussed in the interview so as to extract the most significant indicators representing the quality benchmark for unsafe slums, taking into account the limited designated investments and the temporary situation of such slums. Participants were asked to suggestthe proper interventions required to meet those indicators and, hence, enhance the living conditions without jeopardizing rooting the community in unsafe places. Finally, data was analyzed in an integrative process using qualitative tools to fulfill the aim of the research.

\section{Results}

\subsection{QoL Indicators and Benchmark for Unsafe Areas}

As shown in Table 3, according to the interviews conducted to ISDF and GOPP representatives, it has been noted that there is a general belief that there is no need for enhancing the quality of life of the unsafe areas. Representatives explained that since the slums are to be relocated, hence, any intervention would be consideredmisallocation of the governate resources. This perspectivecould be interpreted by the very limited funds assigned to ISDF, creating a conservative attitude towards spending some of their resources on enhancing the existing settings. However, by the end of the interview, there was a slight agreement on marginal interventions tackling the environmental issues. Representatives stressed on that the environmental interventions would be temporary and financed by community-based involvement. One the other hand, both urban planning experts and local authorities representatives strongly agreed on minimal interventions, which could enhance the quality of life without risking attaching the community to unsafesettings. In this context, the utility provision was the highest priority 
of all QoL categories. They agreed on the importance of maintaining people's health, which would be threatened by the lack of adequate access to safe drinking water and sanitation, along with the absence of solid waste management. However, instead of the traditional infrastructure networks, innovative sustainable alternatives, with the lowest possible cost, were strongly recommended:

- Water tanks delivery on regular basis, and public taps installment as alternative water sources.

- $\quad$ Sewer trenches, and sewage septic tanks as alternative sanitation disposal.

Nevertheless, electricity provision was debatable; some argued that the benchmark of the quality of life should be limitedto maintaining people's health, excluding electricpower,while others agreed as long as innovative cheap approaches are adopted. Moreover, maintaining these interventions was a great concern; for that, utility management was considered a priority; as the absence of maintenance and the poor management of solid waste and sanitation disposal could increase the environmental deterioration of those areas. Consequently, coordination and cooperation between local authorities and the community are required and participatory urban management of such interventions is needed to sustain the slight enhancement of the slums quality of life. While mobility, natural environment, and biodiversity goals were perceived as less needed and could be passed over, the rest goals (safety, shelter, social services) were perceived as risk issues; which could contribute to rooting the local community in the undesired areas.

Table 3. QoL Priorities for Unsafe Areas According to Interview Results

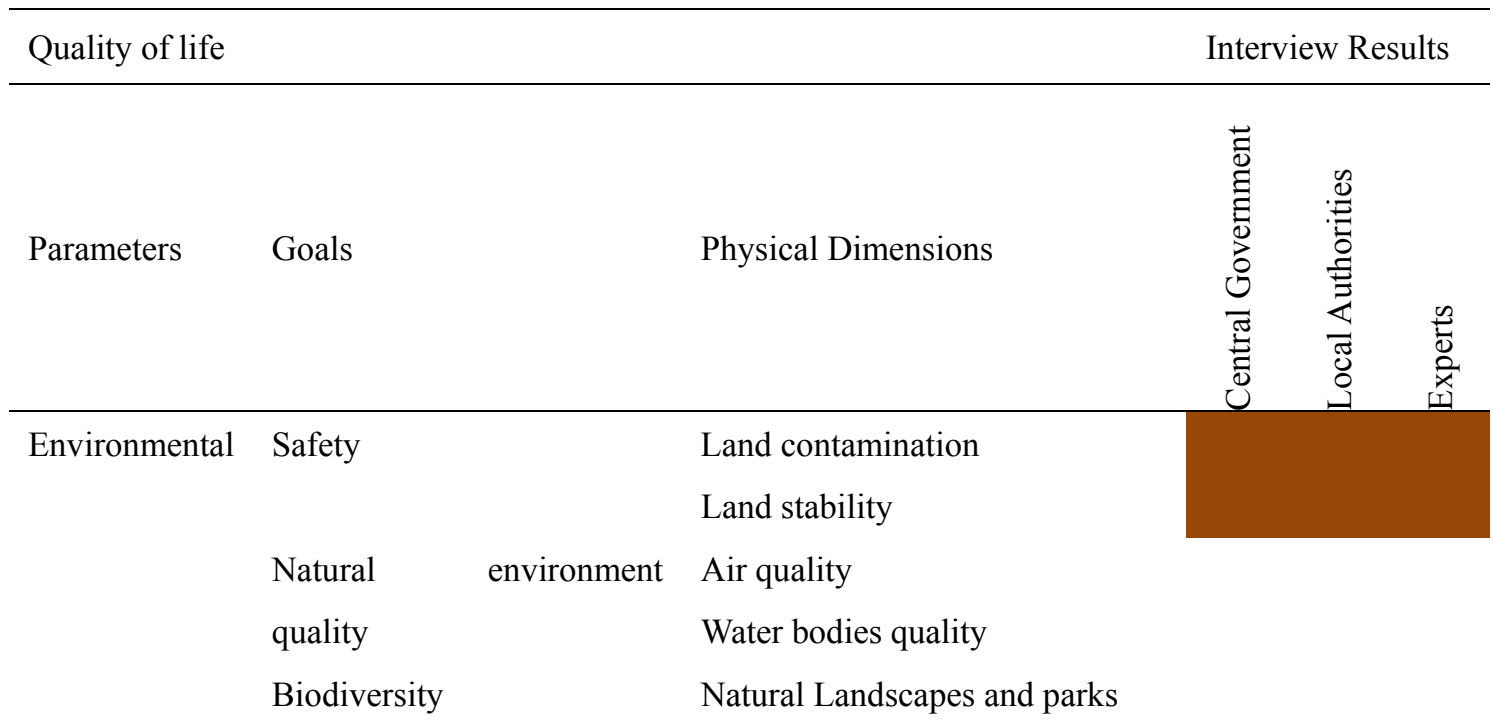

Health

Drinking water access

Drainage

Sanitation

Solid waste management

Social

Shelter

Lighting 


\begin{tabular}{|c|c|c|c|}
\hline & & Density & \\
\hline & & Ventilation & \\
\hline & & Area, design and materials & \\
\hline & & Privacy & \\
\hline & Mobility & Street quality & \\
\hline & & Walkable Network & \\
\hline & & Accessible public transportation & \\
\hline & & Variety of Transportation & \\
\hline & & Choices & \\
\hline & Education & Educational services & \\
\hline & Heath & Health services & \\
\hline & Social interaction & Cultural and recreational services & \\
\hline & & Commercial services & \\
\hline & Culture & Social services & \\
\hline Economic & Income & Job opportunity & \\
\hline & & Energy efficiency & \\
\hline & High priority & & Less priority \\
\hline & Neutral & & Risk issues \\
\hline
\end{tabular}

Source: Researches.

\section{Discussion and Conclusion}

The paper is an attempt to determine the quality of life indicators and benchmarks for unsafeslum areas to be relocated or subjected to clearance policies. The temporary status of those areas has widely affected the results of the study, leading to developing the "Slums Quality of Life Paradigm (SQoLP)"; where QoL indicators are ranked according to their effect on rooting the local community, as shown in Figure 5. Unlike the QoL paradigm (addressed in literature); the indicators in SQoL are totally reversed: the environmental issues are the basic/highest priority, followed by the economic issues, then the social community-related issues. In this context, the degree of attachment to land achieved from certain interventions can reflectthe equivalent strategy required to a specific slum area. In the case of relocation or clearance strategy, the temporary interventions for the existing settings should not contribute to rooting the community and, hence, should be limited to the environmental issues, especially those related to people's health. While in the case of in-situ upgrading strategy, the socio-economic issues should be tackled; especially those related to jobs generation and social networks enhancement.Accordingly, safety in this paradigm is not a one package; life threat is distinguished from social threat. The former is concerned with vulnerability to natural disasters, and as mentioned before, immediate displacement is compulsory and, hence, the minimal (or even temporary) 
enhancements are not applicable in this case. While the latter is mainly concerned with the security of tenure which plays a crucial role in rooting the community and, hence, it is considered as one of the socio-economic issues.

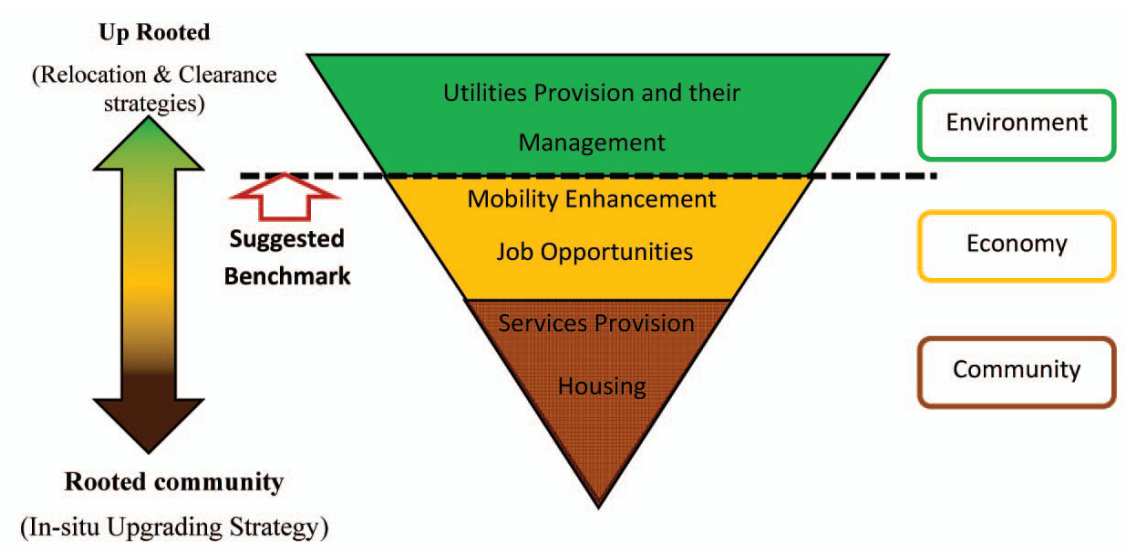

Figure 5. The Proposed Quality of Life Paradigm for Slum Areas

Source: Authors.

Within this paradigm, innovative sustainable alternatives for utility provision, along with managing and maintaining those interventions should be the benchmark of the substantial SQoL indicators for unsafe areas subject to clearance or relocation. However, to adopt this paradigm, social norms, attitudes and values of different parties (central, local authorities, experts and local communities) should be revisited, and a participatory people-centered approach should be implemented; where all stakeholders share the responsibility, and all community sectors can optain a better quality of life.

\section{References}

Amao, F. (2012). Housing Quality in Informal Settlements and Urban Upgrading in Ibadan, Nigeria, A Case Study of Apete in Ibadan. Developing Country Studies, 2(10).

Amao, F. (2014). Quality of Life of Poor Residential Neighborhoods in Oshogbo, Nigeria. World Academy of Science, Engineering and Technology. International Journal of Social, Behavioral, Educational, Economic, Business and Industrial Engineering, 8(4).

Bradburn, N. (1969). The Structure of Psychological Well-Being (Aldine, Chicago).

Brickman, P., Coates, D., \& Janoff-Bulman, R. J. (1978). Lottery winners and accident victims: Is happiness relative. Journal of Personality and Social Psychology, 36, 917-919. https://doi.org/10.1037/0022-3514.36.8.917

Central Agency for Public Mobilization and Statistics (CAPMAS). (2008). Studying the Slum Areas in Egypt (in Arabic).

Craglia, M., Leontidou, L., Nuvolati, G., \& Schweikar, T. J. (2004). Towards the development of quality of life indicators in the "igital" city. Environment and Planning B: Planning and Design. 
https://doi.org/10.1037/0022-3514.36.8.917

Darkey, D., \& Kariuki, A. (2013). A Study on Quality of Life in Mathare, Nairobi, Kenya.Kamla-Raj. $J$ Hum Ecol, 41(3), 207-219.

Diener, E., \& Suh, E. (1997). Measuring Quality of Life: Economic, Social, and Subjective Indicators. Social Indicators Research (pp. 189-216). Existing Slums and Reducing the Need for Future Slums, paper presented at Urban Research. https://doi.org/10.1023/A:1006859511756

Doi, K., Kii, M., \& Nakanishi, H. (2008). An integrated evaluation method of accessibility, quality of life, and social interaction. Environment and Planning B: Planning and Design, 1098-1116. https://doi.org/10.1023/A:1006859511756

El Ariane, S. (2012). Neighborhood Urban Quality of Life, Guidelines for Urban Planning and Development of New Assessment Tool (Unpublished Doctoral Thesis). Faculty of Engineering, Cairo University Giza, Egypt

El-Framawy, A., \& Algohary, S. (2011). Egyptian approach to informal settlements development. ISDF, Egyptian Cabinet of Ministers.

Flynn, P., Berry, D., \& Heintz, T. (2002). Sustainability \& Quality of Life Indicators, toward the Integration of Economic, Social and Environmental Measures. The Journal of Social Health, 1(4).

General Organization for Physical Planning (GOPP). (2012). Greater Cairo Urban Development Strategy: Part (1). Future Vision and Strategy Directions. Egypt.

Hardi, P., \& Pinter, L. (2007). City of Winnipeg, Quality of Life Indicators, Community Quality-of-Life Indicators (pp. 127-157). Canada.

Informal Settlement Development Facility (ISDF). (2009a). Terms of references for data collection of slum areas (unsafe and unplanned) in the governorates of the republic.

Informal Settlement Development Facility (ISDF). (2009b). Workshop on explaining the mechanism of monitoring and evaluation the development projects of unsafe areas. 15 the 16th November 2009. Cairo, Egypt.

Informal Settlement Development Facility (ISDF). (2010). The National Plan national for Dealing with Unsafe Areas. ISDF.

Informal Settlement Development Facility (ISDF). (2014). Data and GIS for Informal Areas Development in Egypt. ISDF.

Japan International Cooperation Agency JICA. (2011). Data Collection Survey Mission on Slum and Informal Area Development in the Greater Cairo Region (Final Report).

Jha, D., \& Tripathi, V. (2014). Quality of Life in Slums of Varanasi City: A Comparative Study, Trans. Inst. Indian Geographers, 36(2).

Khalifa, M. (2011). Redefining Slums in Egypt: Unplanned Versus Unsafe Areas. Habitat International, 35(2011), 40-49. https://doi.org/10.1016/j.habitatint.2010.03.004

Moser, G. (2009). Quality of Life and Sustainability: Toward Person-Environment Congruity. Paris Descartes University, Laboratory of Environmental Psychology, CNRS, UMR 8069, France. 
https://doi.org/10.1016/j.jenvp.2009.02.002

Nakanishi, H. (2013). Planning And Quality of Life: The Case Of Canberra. University of Canberra, Australia Centennial Canberra-Past, Present and Future Workshop, Australia.

Owoeye, J., \& Ogundiran, A. (2015). A Study On Housing And Environmental Quality Of Moniya Community In Ibadan. Nigeria, International Journal Of Physical And Human Geography, 3(1), $31-45$.

Patel, S. (2014). Better Measures for Urban Quality of Life: The View From Below. Development Progrese Organization, UK.

Sims, D. (2010). Understanding Cairo: The Logic of a City out of Control. The American University in Cairo Press, Cairo.

Sundari, S. (2003). Quality Of Life of Migrant Households in Urban Slums. In Proceedings of the Third International Conference on Environment and Health (pp. 537-552). Chennai, India,

UN Organization. (2015). Millennium Development Goals, Goal 7. Ensure Environmental Sustainability.

UN-Habitat. (2003). The Challenge of Slums: Global Report on Human Settlements. Earths can Publications Ltd, UK.

UN-Habitat. (2008). State of the World's Cities 2008/2009: Harmonious Cities. Earthscan Publications Ltd, UK.

Westaway, M. (2006). A Longitudinal Investigation of Satisfaction with Personal and Environmental Quality Of Life in an Informal South African Housing Settlement, Doornkoop, Soweto. Habitat International. https://doi.org/10.1016/j.habitatint.2004.09.003 